\title{
Monitoring and Forecasting of Seasonal Rice Crop Productivity for Paddy Dominated Regions of India
}

\author{
Narendra N. Das (Jet Propulsion Laboratory, NASA) \\ Konstantinos Andreadis (University of Massachusetts Amherst) \\ Amor Ines (Michigan State University)
}

\section{Keywords:}

Crop Modeling, Hydrologic Modeling, Rice Yield, Seasonal Forecasting, Remote Sensing

\begin{abstract}
:
The relevance of this study is immense for India. The Indian economy largely depends on agriculture, which is impacted by weather extremes and variability in monsoon. India is more vulnerable to disruption from drought than countries like the United States. While agriculture accounts for just 16 percent of India's economy, half of its 1.3 billion people work on farms, thus, making agriculture the backbone of the Indian economy. However, in agriculture, rice is India's most important food crop with nearly 1 billion Indian people reliant on it as their major food source. Most important constraint to rice production is water stress which affects nearly $\sim 40$ million ha of rainfed system from the total $\sim 45$ million ha area under rice cultivation. Future climate change effects on rainfall timing and amount, and projected increases in temperature are expected to exacerbate existing water stresses and will have a direct impact on agriculture in India, especially rice cultivation. We have developed an integrated system that is successfully implemented in many countries. The integrated system RHEAS (Regional Hydrological Extreme and Assessment System) coupled with M-DSSAT (modified DSSAT crop model) ingests various NASA Earth science data to produce a set of relevant hydrologic products (e.g., drought indices, water excess/stress information) and rice yields nowcasts (current conditions), forecasts, and seasonal projections, and then feed them into the operational agency. The overarching goal of this study is to provide this integrated system to stakeholder to improve decision-making process and mitigate the plights of rice farmers and prepare the country to deal with ground realities based on the forecast of rice production.
\end{abstract}

\section{Introduction:}

Indian economy largely depends on agriculture, which is impacted by weather extremes and variability in monsoon. India is more vulnerable to disruption from drought than countries like the United States. While agriculture accounts for just 16 percent of India's economy, half of its 1.3 billion people work on farms, thus, making agriculture the backbone of the Indian economy. However, in agriculture, rice is India's most important food crop with nearly 1 billion Indian people reliant on it as their major food source. Most important constraint to rice production is water stress which affects nearly $\sim 40$ million ha of rainfed system from the total $\sim 45$ million ha area under rice cultivation [1]. As illustrated in Fig. 1, future climate change effects on rainfall timing and amount, and projected increases in temperature are expected to
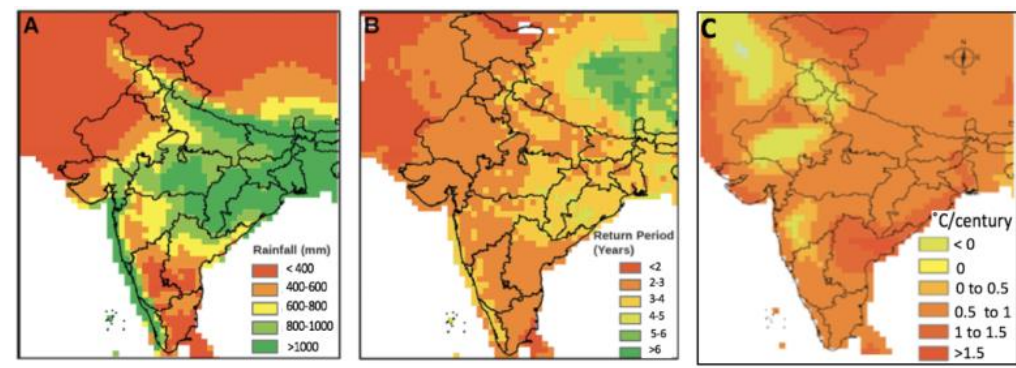

Figure 1: Changing climate trends in India. A) The expected monsoon rainfall ( $\mathrm{mm} /$ year); B) Return period of $10 \%$ departure from the mean rainfall; and C) The rate of change in mean annual temperature $\left({ }^{\circ} \mathrm{C} /\right.$ century). exacerbate existing water stresses and will have a direct impact on agriculture in India [2], especially rice cultivation. India is also a major producer (second largest rice producer) and an important player in the global agriculture 
market, and with the integration of the world economies it is of strategic interest for the world to have an optimal forecast and assessment of agricultural production in India.

Understanding the significance and urgency of the situation, a physically-based, integrated hydrologic and crop modeling framework is essential that is at advanced Application Readiness Level. The integrated hydrologic and crop modeling framework will ingest the best available NASA Earth science remotely sensed data products (e.g., SMAP, GPM IMERG, CHIRPS, TMPA, MODIS LAI/FPAR) to produce a set of relevant hydrologic variables (e.g., various drought indices, water excess/stress information) and crop yields nowcasts (current conditions), forecasts, and seasonal projections, and then feed them to the operational agency. These vital information is then will be useful for: i) assessment, early warning, and risks for agricultural droughts and outlooks of agricultural water demands in the rice cultivated regions of India; and ii) rice crop monitoring, seasonal yield forecasting, and final yield estimation. These critical information enable the stakeholders and policy-makers at the federal- and statelevel to: i) delineate drought-prone and drought-affected regions; ii) make crucial decisions in advance on distribution of drought-resistant seeds to the farmers of affected regions; (iii) providing subsidies for fertilizers and seeds; and (iv) distribution of monetary relief (insurance) to farmers in case of crop loss due to water stress and drought situations.

Narrative: The changing climate and monsoon patterns in India have become a major concern for farmers, scientists, and policy-makers [3, 4, and 5]. For instance, researchers at the India Meteorological Department (IMD)-Pune, which handles long-range climate forecasts, have concluded that the June-September monsoon is increasingly becoming more sluggish in its initial phase, then picking up pace towards the end of the season [7, 8, and 9]. For a good harvest, the monsoon must not only be timely but also evenly distributed across the vast regions of the food-bowl states of India. Given current farming practices, a good knowledge of upcoming geophysical events (e.g., expected rainfall, drought outlooks) for June and July is vital, as during that period farmers sow a variety of crops, such as rice, maize, and pulses. Uncertainties in seasonal climate forecast and occurrence of frequent droughts have also made the situation critical. These changes in climate have pushed India's agriculture sector towards a tipping point and it must now be prepared to face the challenges by upgrading existing systems and tools to keep feeding a billion-plus population. Therefore, it is crucial to have a reliable and comprehensive forecasting model that uses cutting edge tools, physically-based models and reliable satellite-based remote sensing data to provide a skillful forecast of water stress and seasonal (1 to 3 months in advance) crop yield estimates.

The current system (FASAL from ISRO) lacks seasonal crop and drought forecasting component, and this limitations stems from unavailability of an integrated physically-based hydrologic and crop modeling framework with forecasting capability. We propose a physically-based, integrated hydrologic and crop modeling framework that essentially factor in all major influencing attributes for modeling seasonal rice yield forecast and estimation, and related drought status. The integrated model extends flexibility to run scenarios to optimize the rice yield and broadcast advisories to farmers. The integrated framework enables key information to decision-makers to take effective measures to deal with the impending situation to optimize crop yield and protect farmers.

Based on these contexts, this study advances the use of satellite observations and hydrologic modeling to monitor and assess local and regional water quantity for improving risk assessment, economic planning, investment planning, and policy making. Therefore, a physically-based coupled hydrologic and crop model named as the Regional Hydrologic Extremes Assessment System (RHEAS) [10] coupled with the Modified-DSSAT (M-DSSAT) [11], as shown in Fig. 2 for nowcasts and forecasts using the best available ground-and satellite-based information for the rice producing regions of India is implemented. The RHEAS and M-DSSAT software architecture and its major components are coded in Python and the model outputs are stored in a GIS-enabled relational database (PostGIS). The design choice has several advantages: (i) system modularity since any model added to RHEAS needs to only 
interface with the database and not any other model internal formats; (ii) GIS functionality that allows spatial operations, complex queries and analytics; (iii) the ability to serve data through well-established web technologies. The design allows seamless coupling of the core hydrologic model with other models extending the system's applicability. All models in RHEAS retrieve their input and store their output in a PostGIS database. The datasets that are not produced by the RHEAS models, including satellite observations are automatically fetched and ingested into the PostGIS database.

The logic of integrating the hydrologic model (HM) in RHEAS and crop model (CSM) in MDSSAT is to capture the whole gamut of hydrological processes and the full extent of process dynamics involved in the soil-plant-atmosphere continuum. Figure 2 illustrates a simplified flow diagram of the integrated framework. We selected a widely-used HM, the Variable Infiltration Capacity (VIC) (Liang et al., 1994) model, and for the crop model, we selected a widely used CSM, the Decision Support System for Agrotechnology Transfer - Cropping System Model (DSSAT) [11]. They both are physically-based models and can run in nowcast and forecast modes.

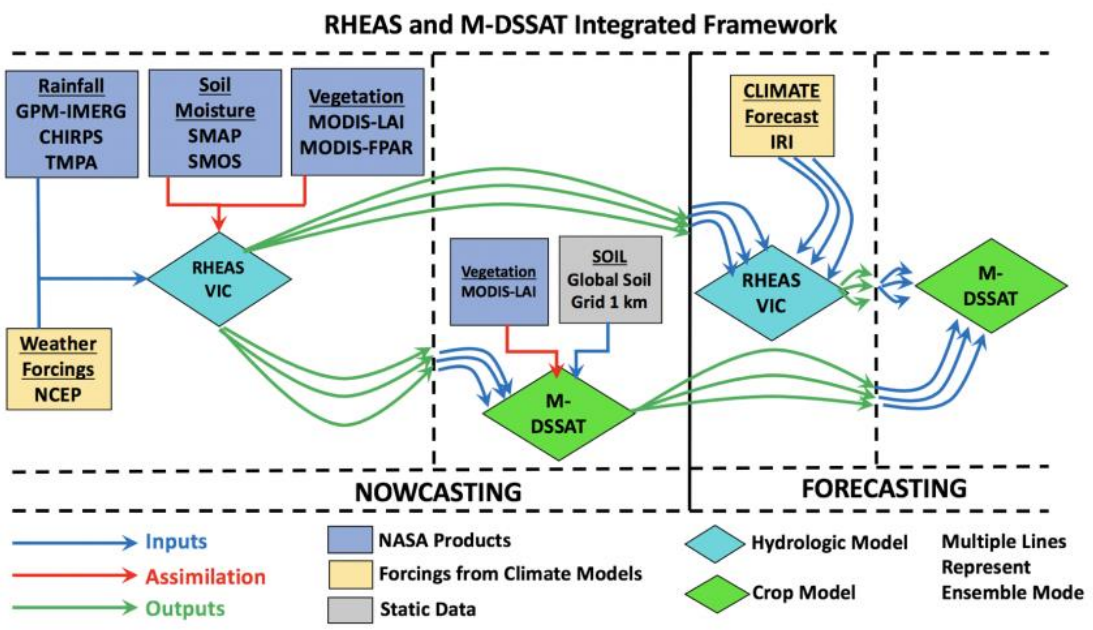

Figure 2: Integrated model (RHEAS) and M-DSSAT, and system architecture developed at JPL that makes the coupled hydrologic and crop models run in nowcast and forecast mode (Konstantinos, Das et al., 2017) [10] (https://journals.plos.org/plosone/article?id=10.1371/journal.pone.0176506)

\section{Hydrologic Modeling:} The VIC model is a largescale, semi-distributed hydrologic model that solves the full water and energy balances of a study domain under consideration. VIC allows the estimation of a multitude of hydrologic variables and a suite of water availability indicators that encompass the variability and characteristics of the entire water cycle. These variables and indicators are constrained by satellite and in situ observations of the hydrological cycle: precipitation, snow (if needed), ET, soil moisture, groundwater, and runoff. Figure 3 and Fig. 4 show the current capability of the the RHEAS and M-DSSAT framework.
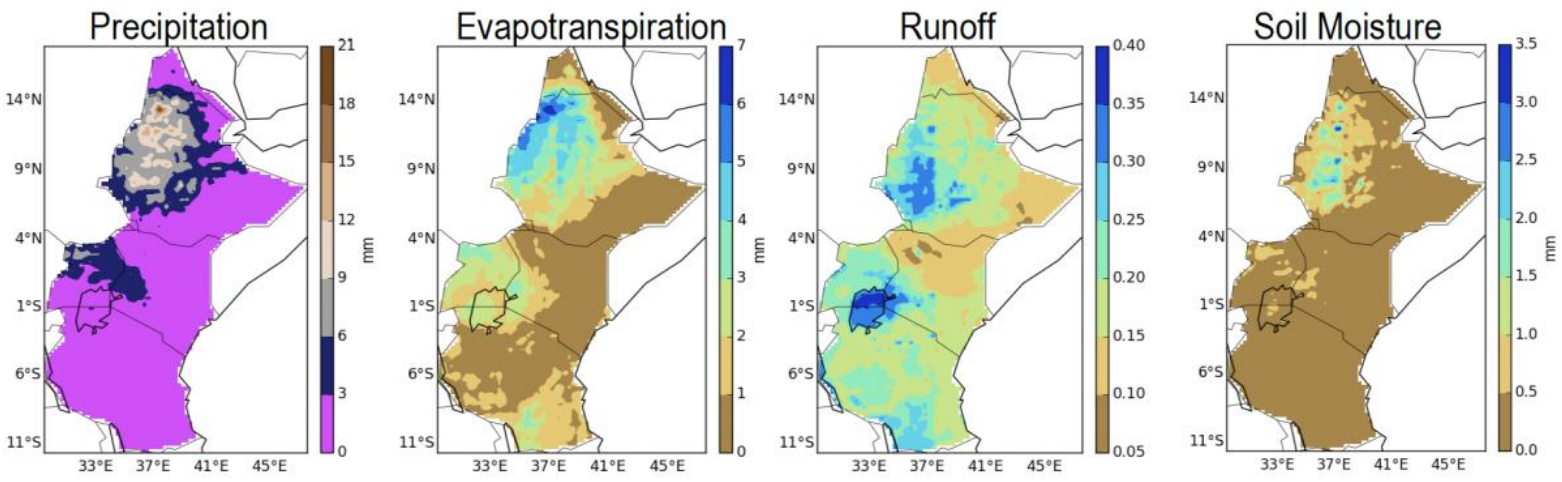

Figure 3: Capability of RHEAS framework, example from operational system in theEast Africa region, the figure shows nowcasts of hydrologic outputs of the RHEAS system. 


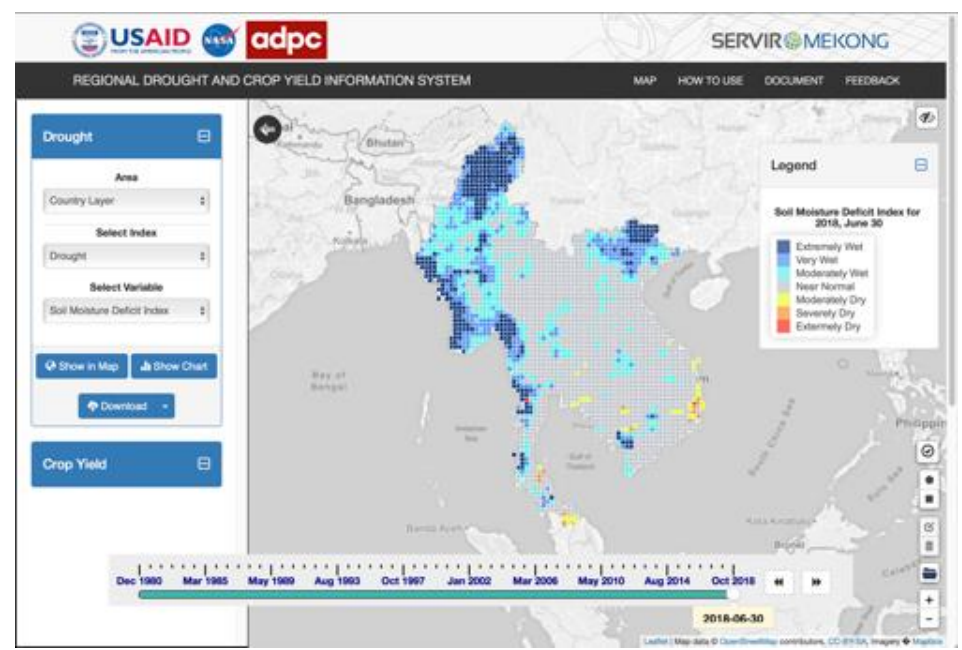

Figure 4: Operational RHEAS system from the Southeast Asia Hub, nowcasts of hydrologic output (SMDI) of the RHEAS system. The web-based system is operational. The online portal is available at https://rdcyis-servir.adpc.net.

The minimum input requirements for VIC include precipitation, air temperature and wind speed, which can either be provided by the satellite data products (if available) or reanalysis from the National Center for Environmental Prediction (NCEP) datasets [12]. The temporal resolution of VIC will be daily since droughts are relatively persistent events that require daily precipitation to be captured by a hydrologic model. ET and soil moisture are prognostic variables in VIC, but can be corrected using the satellite observations and an optimal estimation technique. The spatial resolution of the model simulation for this project will be 5 and $25 \mathrm{~km}$, and is primarily governed by the available precipitation products.

Crop Modeling: In the integrated system, RHEAS output (obtained from assimilating remote sensing observations) from VIC is used to initialize the surface boundary conditions and rootzone profiles of the crop model, i.e., Modified-DSSAT (M-DSSAT). The coupled M-DSSAT is also linked with an Ensemble Kalman Filter (EnKF) to assimilate profile soil moisture (from VIC) and vegetation related attributes (e.g., MODIS LAI), as illustrated in Fig. 5. The VIC and the M-DSSAT in the modeling framework (Fig. 2) use the same forcings. (NOTE: The original DSSAT model is modified to become M-DSSAT that accommodate EnKF with 50 ensemble members)

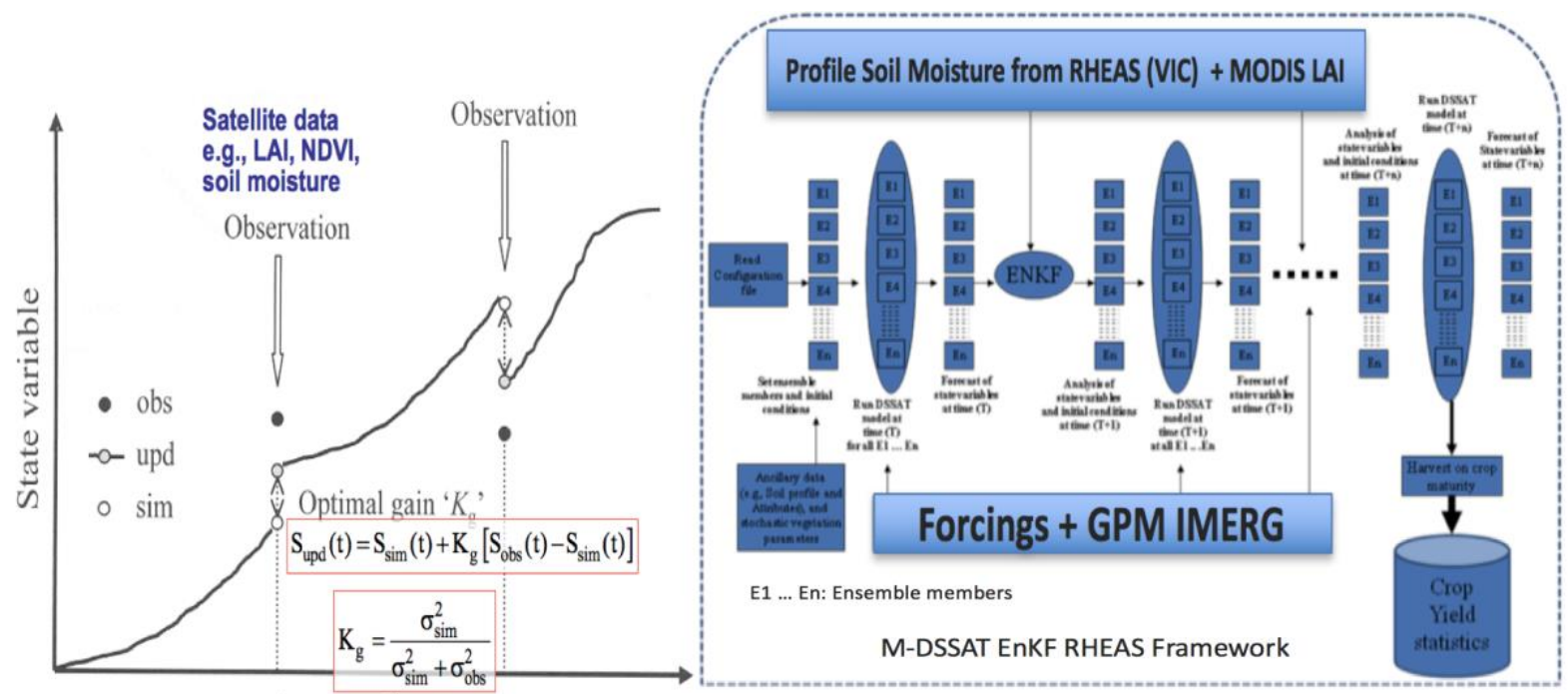

Figure 5: M-DSSAT crop model of the RHEAS framework. It is capable of 50 ensembles (E in the figure), optimal to capture the variability in agricultural system within an administrative unit [13].

The integrated framework's crop modeling component (M-DSSAT) simulates growth, development, and yield of a crop, under given management practices, weather and 
environmental conditions, e.g., soil fertility, soil water holding capacity, etc. The crop model is equipped with its own soil hydrology module that interacts with the crop component that simulates plant's phenology, morphology, and yield. Ensembles are made in the M-DSSAT that capture the variability in the agricultural system due to various model parameters, soil profile, uncertainty in planting dates, fertilizer application and different types of seeds (cultivars). Crop models are generally designed to run continuously from sowing until maturity and harvest. Therefore, it is expected that by moving towards harvest season, the history of crop growth captured by model helps the M-DSSAT to produce a more realistic crop yield forecast than what could otherwise be obtained by just using model-based forcing from seasonal climate forecast. It should be noted that to incorporate M-DSSAT in the integrated framework, we have customized to stop on any given day to facilitate data assimilation (EnKF) when desired and restarts from that point in time [13]. As illustrated in Fig 5, the M-DSSAT of the integrated system is also implemented for the East Africa region and the Southeast Asia. Table 1 provides a list of datasets that are used to obtain the products shown above (Figures 3 , 4, and 6). For the proposed work, We plan to use the similar inputs of NASA remote sensing observations and geophysical data. These datasets are most advanced and optimally accurate with thorough quality control. Ingestion as inputs to the integrated framework will add significant value to the water and agricultural decision-making agencies.
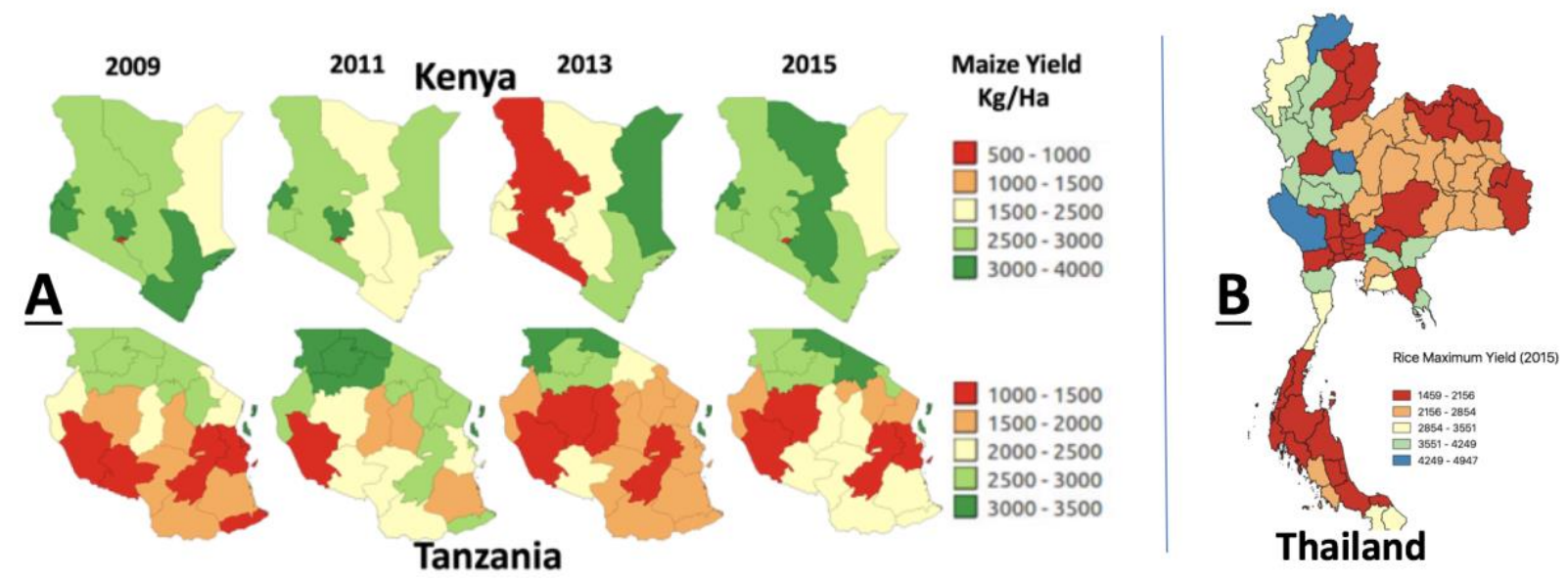

Figure 6: Operational M-DSSAT system from the, crop yields obtained from the integrated RHEAS and M-DSSAT framework: A) Maize yields from Kenya and Tanzania; and B) Rice yields from Thailand.

Table 1: NASA products used in the RHEAS and M-DSSAT.

\begin{tabular}{|l|l|l|l|l|}
\hline \multicolumn{2}{|l}{ Variable } & Product & \multicolumn{3}{l}{ Spatial } \\
Resolution & \multicolumn{1}{l}{ Temporal } & Perolution Available \\
\hline Precipitation & GPM IMERG & $10 \mathrm{~km}$ & Daily & 2014 - Present \\
\hline & TMPA & $25 \mathrm{~km}$ & Daily & 1998 - Present \\
\hline & CMORPH & $8 \mathrm{~km}$ & Daily & 1998 - Present \\
\hline & CHIRPS & $5 \mathrm{~km}$ & Daily & 1981 - Present \\
\hline & PERSIANN-CDR & $25 \mathrm{~km}$ & Daily & 1983 - Present \\
\hline Temperatre & NCEP & $1.875 \mathrm{deg}$ & Daily & 1948 - Present \\
\hline Wind Speed & NCEP & $1.875 \mathrm{deg}$ & Daily & 1948 - Present \\
\hline Soil Moisture & SMAP & $\sim 9 \mathrm{~km}$ & $2-3$ days & 2015 - Present \\
\hline & SMOS & $40 \mathrm{~km}$ & $2-3$ days & 2010 - Present \\
\hline Evaportranspiration & MOD16 & $1 \mathrm{~km}$ & 8 days & 2000 - Present \\
\hline Leaf Area Index & MCD15 & $1 \mathrm{~km}$ & 8 days & 2002 - Present \\
\hline Seasonal Climate Forecast & IRI & 2.5 & Monthly & 2000 - Present \\
\hline
\end{tabular}

A study was conducted to evaluate the performance of the RHEAS and M-DSSAT framework for the rice producing states of India._The results are shown in the following Figs 7 10. The study areas are among the major rice producing states of India. The rice cultivation is mostly rainfed and depends on onset, duration and intensity of monsoon. 


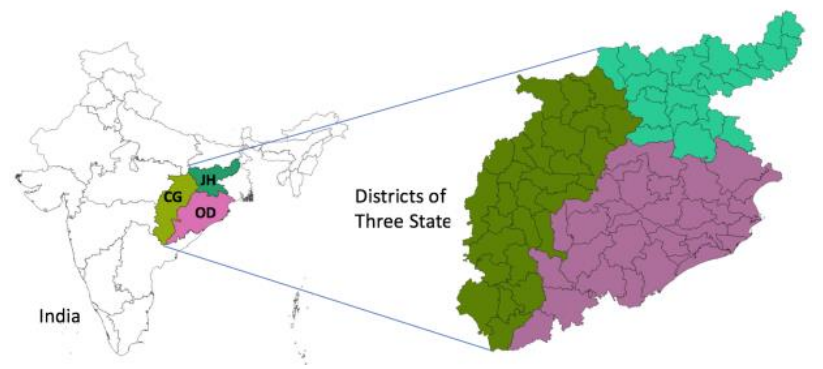

Figure 7: Study area in the eastern part of India that comprises three states. CG Chhattisgarh, OD - Odisha, and JH Jharkhand.

Nowcast simulation where done for 17 years $(2001$ - 2017). Figure 8 illustrates two distinct scenarios. 2012 a below normal monsoon and 2017 an average monsoon year. The RHEAS model clearly captures the impact of below average monsoon in 2012. The drought indicators from 2012 show higher severity (in Jul and Oct), low SPI ( 3-monthly) and low SMDI. The outputs from RHEAS were used as inputs to M-DSSAT. Figure 9 highlights the impact of the drought in terms of rice yields in most of the districts of the three states (CG, OD and JH). The correlation between the drought indicators and the rice yields is significant.
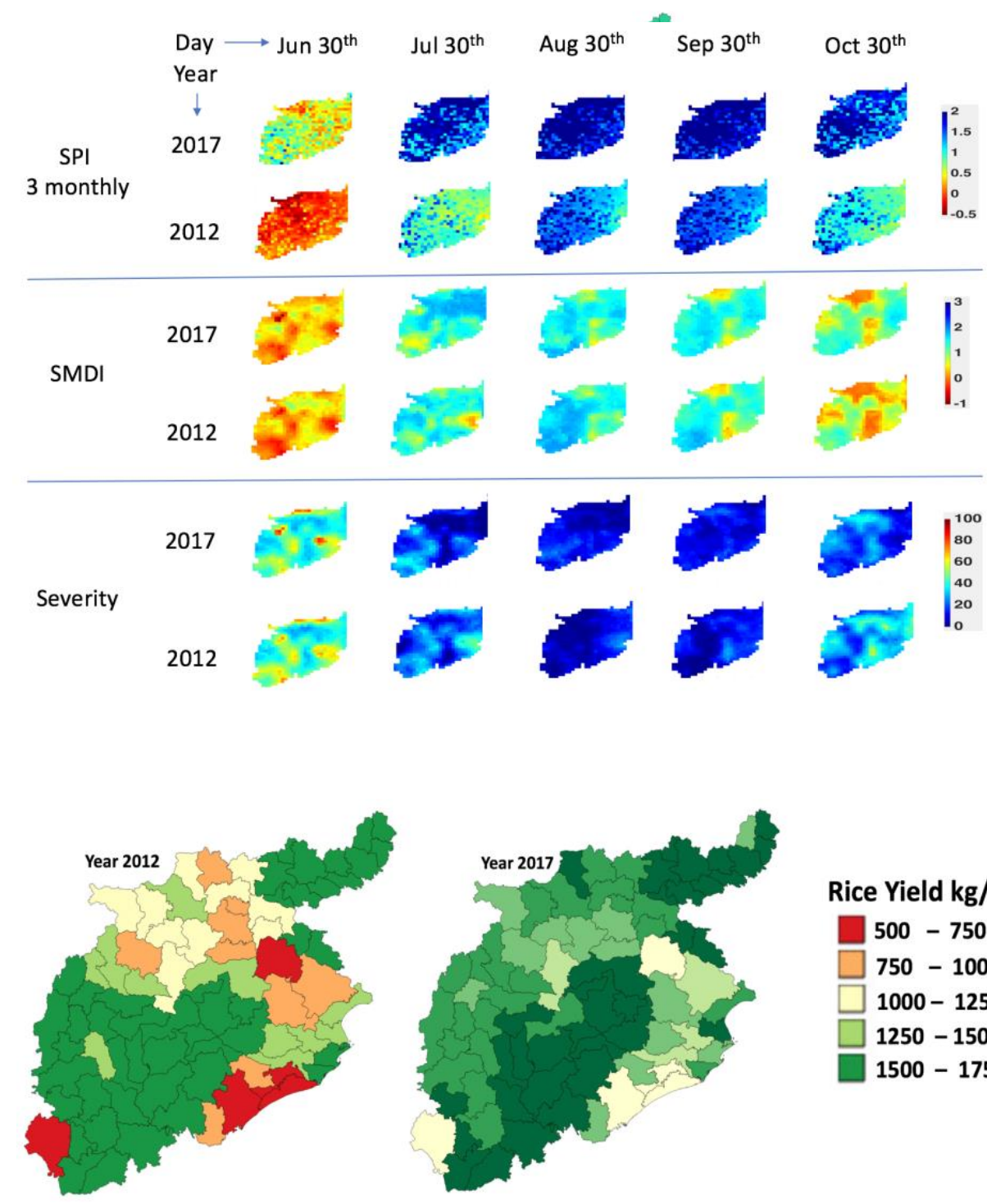

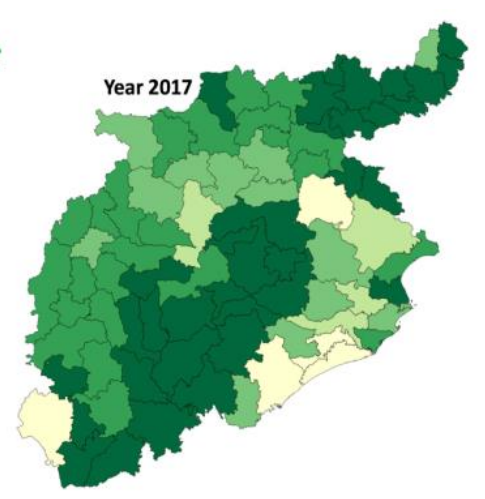

Rice Yield kg/Ha

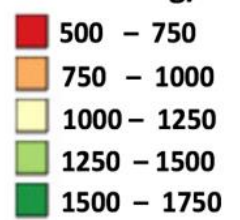

Figure 8: Outputs (water stress and drought indicators) from RHEAS.
Figure 9: Rice yields for years 2012 and 2017 for the three states (CG, OD, and $\mathrm{JH})$. 
Actual rice yields and the simulated yields from the integrated framework are compared in Figure 10. The results demonstrate significant skills of the RHEAS and the M-DSSAT models. Models (VIC and M-DSSAT) calibration will further improve the outputs from the integrated system. The comparison demonstrate that the RHEAS and M-DSSAT system capture in the interannual variability for all the three states. The observed root-mean-square-difference between the simulated and observed is also very low $\sim 300 \mathrm{~kg} / \mathrm{Ha}$ with very high correlation.
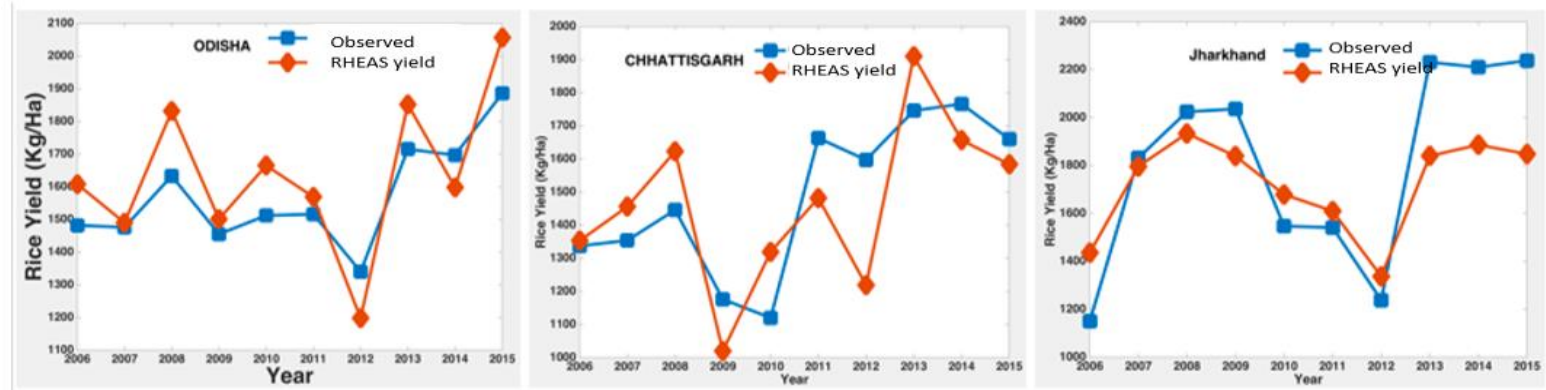

Figure 10: Comparison of actual rice yields and RHEAS and M-DSSAT output yields for three states for year 2006 to year 2015.

The output products from RHEAS and M-DSSAT system (Fig. 2) level includes a large range of hydrologic variables, indicators derived from the core hydrologic variables, and agricultural variables (a list of data products is illustrated in Table 2). Variables that are related directly to water stress are given in absolute values as well as anomalies; these include soil moisture, temperature, and precipitation (as shown in Fig. 11). These are also used to construct common drought indicators such as the Standardized Precipitation Index (SPI), the Palmer Drought Severity Index (PDSI), and the Surface Water Supply Index (SWSI) (see Table 2). Additionally, the fundamental drought characteristics of onset, duration, recovery, and severity are produced directly from RHEAS and M-DSSAT system. Severity (e.g., mild, moderate, severe, extreme) is spatially relative and time varying. Agricultural outputs include estimates of yield, productivity and crop health. Incorporating socioeconomic data to quantify and improve understanding of drought impacts to populations in the Indian rice producing states is of critical importance. The Crop-Drought Vulnerability Index (CDVI), for example, represents the sensitivity of crop productivity to the magnitude of a drought, which also characterizes the resilience of a region in terms of agricultural production [15]. All data products are in GISready formats as GeoTiffs, Shapefiles, and Rasters to facilitate seamless incorporation into existing GIS-enabled web-based or desktop-based toolkits. We will work with our partners to determine the best methods for visualizing and delivering the data products for effective decision-making. RHEAS and M-DSSAT system has all the necessary variables to generate new customized products that will be developed based on the user needs and requirements to optimally guide decision-makers and help formulate policies during exigencies.

\begin{tabular}{|l|l|}
\hline Product & Decision-making activity \\
\hline Crop yields and statistics & $\begin{array}{l}\text { Outlook on the expected yield to support risk } \\
\text { management }\end{array}$ \\
\hline $\begin{array}{l}\text { Drought Indicators, e.g., } \\
\text { CDVI, SRI, SPI, PDSI }\end{array}$ & Understanding impacts of drought on populations \\
\hline $\begin{array}{l}\text { Drought onset, recovery and } \\
\text { duration }\end{array}$ & $\begin{array}{l}\text { Dry conditions control timing of crop, food storage } \\
\text { planning and security }\end{array}$ \\
\hline Drought Severity & $\begin{array}{l}\text { Can control how aggressive actions need to be } \\
\text { alleviate problems }\end{array}$ \\
\hline $\begin{array}{l}\text { Change in soil moisture with } \\
\text { time }\end{array}$ & $\begin{array}{l}\text { Quantify depletion rates and provide outlook on } \\
\text { growth potential, irrigation scheduling, water } \\
\text { allocation to specific regions }\end{array}$ \\
\hline $\begin{array}{l}\text { Soil moisture, temperature, } \\
\text { and precipitation }\end{array}$ & $\begin{array}{l}\text { Determine the break of season, potential for } \\
\text { growth, onset and duration of rapid growth, } \\
\text { planting date, fertilizer application, and harvest }\end{array}$ \\
\hline Greenness/vegetation & $\begin{array}{l}\text { Related to health of crops during the growing } \\
\text { season }\end{array}$ \\
\hline
\end{tabular}

Table 2: Suite of data products from the RHEAS and M-DSSAT system generated within the integrated framework. Products can be extended and customized as per stakeholder's need. 


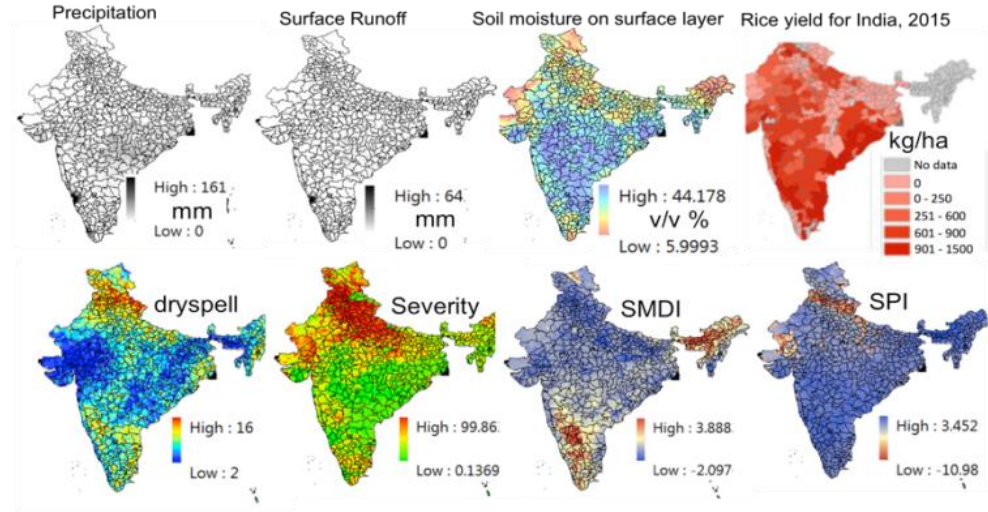

Figure 11: An example of data product from the RHEAS and MDSSAT system ready for implementation and operation. The results are for $15^{\text {th }}$ June, 2015 from the simulation that used the NCEP forcings and CHIRPS precipitation data for five years (2011 to 2015).

\section{Conclusions:}

The coupled RHEAS and M-DSSAT system will be a robust capability for the India and will eliminate the current deficiencies by incorporating: i) advanced remote sensing data and flexibility to choose specific remote sensing data or make an ensemble of remote sensing data as inputs; ii) provide tools to monitor and forecast most of the land surface hydrologic variables, and potential for computing different drought indices (e.g., SPI, SMDI, PDSI, and SWI); iii) capture variability in the hydrologic and crop modeling using ensemble mode of coupled RHEAS and M-DSSAT system; iv) enable tools for skillful seasonal (1 to 3 months) forecast of crop yields with uncertainty bounds based on global short-term and long-term seasonal climate forecast; v) extend capability to run the physically-based models on weekly basis to regularly monitor and update the status of drought and the future crop yields; and vi) impart capability to run decadal scale simulations using different evolving climate scenarios to understand water use/stress/demand and crop yields trend based on different evolving climate scenarios. The RHEAS and M-DSSAT system will also equip our decision making agencies with the integrated framework to run various scenarios in advance to assess the drought and water stress conditions and crop yields when changing the variables and parameters pertaining to planting dates, fertilizer applications, irrigation scheduling, and experimentation of new drought resistant cultivars (seed types) using the projected seasonal climate forecast.

\section{Acknowledgements:}

The work is funded by the NASA SERVIR program and the Jet Propulsion Laboratory, NASA.

\section{References:}

[1] Abrol YP, Gadgil S (eds) (1999) Rice - in a Variable Climate. APC Publishing House, New Delhi, p 252.

[2] Turner, A. G. and Annamalai, H., 2012. Climate change and the South Asian Monsoon, Nature Climate Change 2: 587-595.

[3] Aggarwal, P. K., 2008. Global climate change and Indian agriculture: impacts, adaptation and mitigation. Indian Journal of Agricultural Sciences. 78 (10): 911-919.

[4] Schär, C., and Jendritzky, G., 2004. Climate change: Hot news from summer 2003. Nature , 432, 559-560. 
[5] Christensen, J.H., Hewitson, B., Busuioc, A., Chen, A., Gao, X., Held, I., Jones, R., Koli, R.K., Kwon, W. T., Laprise, R., Rueda, V.M., Mearns, L., Menéndez, C.G., Räisänen, J. , Rinke, A., Sarr, A., and P. Whetton. 2007. Regional climate projections. Climate Change 2007: The Physical Science Basis. Contribution of WorkingGroup I to the Fourth Assessment Report of the Intergovernmental Panel on ClimateChange, S. Solomon, D. Qin, M. Manning, Z. Chen, M. Marquis, K.B. Averyt, M. Tignor and H.L. Miller, Eds.Cambridge University Press, Cambridge. 847-940.

[6] Chaturvedi, R. K., Joshi, J., Jayaraman, M., Bala, G., and Ravindranath, N. H., 2012, "Multi- Model Climate Change Projections for India under Representative Concentration Pathways," Current Science, vol. 103, no. 7, pp. 1-12.

[7] Gadgil, S., 2003, “The Indian Monsoon and its Variability,” Annual Review of Earth Planet Science, vol. 31, pp. 429-67.

[8] Gadgil, S., and Kumar, K. R., 2006, "The Asian Monsoon, Agriculture and Economy," in Wang, B. (ed.), The Asian Monsoon, Springer, Praxis, pp. 651-83.

[9] Singh, D., Tsiang, M., Rajaratam, B., Diffenbaugh, A. S., 2014, Observed changes in extreme wet and dry spells during the South Asian summer monsoon season. Nature Climate Change, 4, 456-461.

[10] Konstantinos A., Das N. N., Stampoulis D, Ines A, Fisher JB, Granger S, et al. (2017), The Regional Hydrologic Extremes Assessment System: A software framework for hydrologic modeling and data assimilation, PLoS ONE 12(5): e0176506, https://doi.org/10.1371/journal.pone.0176506.

[11] Jones J.W., Hoogenboom, G., Porter, C.H., Boote, K. J., Batchelor, W.D., Hunt, L. A., Wilkens, P. W., Singh. U., Gijsman, A. J. and J. T. Ritchie (2003), The DSSAT cropping system model. Eur. J. Agron., 18, 235-2

[12] Kalnay, E., M. Kanamitsu, R. Kistler, W. Collins, D. Deaven, L. Gandin, M. Iredell, S. Saha, G. White, J. Woollen, Y. Zhu, A. Leetmaa, B. Reynolds, M. Chelliah, W. Ebisuzaki, W. Higgins, J. Janowiak, K. Mo, C. Ropelewski, J. Wang, R. Jenne, and D. Joseph, 1996: The NCEP/NCAR 40-Year Reanalysis Project. Bull. Amer. Meteor. Soc., 77, 437-471.

[13] Ines, A.V.M., N. N. Das, J. W. Hansen and E. G. Njoku, 2012, Assimilation of Remotely Sensed Soil Moisture and Vegetation with a Crop Simulation Model, submitted to Remote Sensing of Environment, Volume 138, November 2013, Pages 149-164.

[14] Morgan, M.G., Henrion, M., Small, M., 1990, Uncertainty: A Guide to Dealing with Uncertainty in Quantitative Risk and Policy Analysis. doi:10. 1016/0169-2070(92)90021-Z.

[15] Simelton, E., E. D. Fraser, M. Termansen, P. M. Forster, and A. J. Dougill, 2009, Typologies of crop-drought vulnerability: an empirical analysis of the socio-economic factors that influence the sensitivity and resilience to drought of three major food crops in China (1961-2001), Environmental Science \& Policy, 12(4), 438-452.

[16] Gardner, J, Dowd, A-M., Mason, C. and Ashworth, P. (2009). A framework for stakeholder

engagement on climate adaptation. CSIRO Climate Adaptation Flagship Working paper No.3. http://www.csiro.au/resources/CAF-working-papers.html. 